Ciência Florestal, Santa Maria, v. 22, n. 3, p. 551-565, jul.-set., 2012

ISSN 0103-9954

\title{
PADRÃO ESPACIAL DE QUATRO FORMAÇÕES FLORESTAIS DO ESTADO DE SÃO PAULO, ATRAVÉS DA FUNÇÃO K DE RIPLEY
}

\author{
SPATIAL PATTERN OF FOUR FOREST COMMUNITIES BY RIPLEY'S K \\ FUNCTION IN SÃO PAULO STATE
}

\author{
Robson Louiz Capretz ${ }^{1}$ João Luís Ferreira Batista ${ }^{2}$ Jaime Felipe Medina Sotomayor ${ }^{3}$ \\ Camila Rossetti da Cunha ${ }^{4}$ Marcos Felipe Nicoletti ${ }^{5}$ Ricardo Ribeiro Rodrigues ${ }^{6}$
}

\section{RESUMO}

Investigar o padrão espacial das árvores, segundo suas classes de tamanho e segundo suas espécies mais abundantes pode fornecer evidências sobre a estrutura da comunidade vegetal, sendo que, o padrão espacial é uma questão-chave para estudos de ecologia florestal. O nível de organização espacial das árvores no ambiente depende de diversos processos ecológicos e características próprias de cada ambiente, de modo que a melhor compreensão deste quadro fornece subsídios importantes para o conhecimento sobre formações florestais. Neste trabalho objetivou-se estudar o padrão espacial das árvores, segundo suas classes de diâmetro e das quatro espécies mais abundantes em diferentes florestas, visando fornecer evidências sobre a ecologia de cada comunidade vegetal. A descrição do padrão espacial em cada formação florestal foi realizada segundo a Função K de Ripley. As formações florestais estudadas foram: Floresta Ombrófila, Cerradão, Floresta Estacional e Restinga. Instalou-se uma parcela de 10,24 ha em cada formação florestal, e todas as árvores com circunferência na altura do peito (CAP) a partir de $15 \mathrm{~cm}$ foram medidas, georreferenciadas e identificadas. Os resultados obtidos ressaltam o caráter agregado em florestas tropicais, como foi observado em todas as florestas estudadas. As árvores do Cerradão e da Restinga apresentaram padrões de agregação muito próximos. Para a Floresta Ombrófila, o padrão agregado foi significativo em toda a escala de distâncias estudada. Na Floresta Estacional, foi observada tendência à aleatoriedade, embora, uma agregação significativa tenha sido notada para curtas distâncias. O padrão espacial por classes de diâmetro foi, em linhas gerais, agregado para árvores menores que $10 \mathrm{~cm}$ de diâmetro, e entre 10 e 20 $\mathrm{cm}$, e aleatório para as demais, evidenciando uma tendência de que árvores jovens são mais agregadas do que árvores adultas. O padrão espacial das espécies dominantes é sempre muito semelhante ao padrão geral de cada formação florestal. As diferenças entre o padrão espacial das espécies dominantes coincidentes entre as formações florestais indicam que seu padrão é influenciado por cada ambiente. Ressaltando-se assim, a importância da sua autoecologia e dos processos ecológicos intrínsecos a cada comunidade que podem explicar os padrões observados.

Palavras-chave: ecologia florestal; estrutura populacional; análise espacial; floresta tropical.

1. Engenheiro Florestal, Pesquisador da Sociedade de Pesquisa em Vida Selvagem e Educação Ambiental, Rua Desembargador Isaias Bevilaqua, 999, Mercês, CEP 80430-040, Curitiba (PR). robson.capretz@hotmail.com

2. Engenheiro Florestal, PhD., Professor Doutor do Departamento de Ciências Florestais, Escola de Agricultura "Luiz de Queiroz", Universidade de São Paulo, Caixa Postal 09, CEP 13400-970, Piracicaba (SP). parsival@usp.br

3. Engenheiro Agropecuário, Doutorando do Programa de Pós-graduação em Recursos Florestais, Escola Superior de Agricultura "Luiz de Queiroz", Universidade de São Paulo, Av. Pádua Dias, 11, CEP 13418-900, Piracicaba (SP). Bolsista do CPNq. sotomayo@usp.br

4. Engenheira Florestal, Mestranda do Programa de Pós-graduação em Recursos Florestais, Escola Superior de Agricultura "Luiz de Queiroz", Universidade de São Paulo, Av. Pádua Dias, 11, CEP 13418-900, Piracicaba (SP). Bolsista do IPEF. cacaflorestal@usp.br

5. Engenheiro Florestal, Mestrando do Programa de Pós-graduação em Engenharia Florestal, Escola Superior de Agricultura "Luiz de Queiroz", Universidade de São Paulo, Av. Pádua Dias, 11, CEP 13418-900, Piracicaba (SP). Bolsista CAPES. mfnicoletti@usp.br

6. Biólogo, Dr, Professor Titular do Departamento de Ciências Biológicas, Escola Superior de Agricultura "Luiz de Queiroz", Universidade de São Paulo, Caixa Postal 09, CEP 13400-970, Piracicaba (SP). rrr@esalq.usp.br

Recebido para publicação em 10/03/2010 e aceito em 13/07/2011 


\begin{abstract}
Investigating tree's spatial patterns according to their size classes and according to their more abundant species can provide evidences about the structure of the vegetal community, since the spatial pattern is a key question for forestry ecology studies. The tree spatial organization patterns on the environment depend on several ecological processes and on the specific characteristics of each environment, so that the best understanding of this frame provides important elements for the knowledge on forestry formation. This paper aimed to study tree spatial patterns, according to the diameter classes and from four most abundant species in different forests, in order to provide evidences regarding to the ecology of each vegetal community. The spatial pattern description in each forestry formation was developed using Ripley's K function. The studied forestry formations were: Ombrophilous Forest, Cerradao, Seasonal Forest and Restinga Forest. In this work, a 10.24 ha plot was installed in each forestry formation, and every tree, with a circumference at breast height $(\mathrm{CBH})$ larger than $15 \mathrm{~cm}$ were measured, georeferenced and identified. The obtained data highlights the aggregated character in tropical forests, as observed in every studied forest. The 'Cerradão' and 'Restinga' forest trees showed close aggregate patterns. In the Ombrophilous forest, for all distance scales, the aggregate pattern was meaningful. In the seasonal forest, a random tendency was observed, although a meaningful aggregation was observed in all short distances. The spatial pattern by diameter classes was generally aggregated for trees smaller than $10 \mathrm{~cm}$ of diameter and between 10 and $20 \mathrm{~cm}$ and random for the others, proving the existence of a tendency which in young trees is more aggregated than in old ones. The spatial pattern of the dominant species is always strongly similar to the general pattern of each forestry formation. The differences between the spatial patterns of two or three coincident species, among the forestry formations, indicate that its pattern is influenced by each different environment. This stands out the importance of its self-ecology and of its ecological processes, intrinsic of each community that can explain the observed patterns.
\end{abstract}

Keywords: forestry ecology; population structure; spatial analysis; tropical forests.

\section{INTRODUÇÃO}

O padrão espacial de árvores é uma questão-chave para estudos de ecologia florestal que permite analisar a estrutura da comunidade em si, conhecer processos ecológicos importantes, como competição, herbivoria e dispersão de sementes (BAROT et al., 1999; SCHWARZ et al., 2003). Variáveis abióticas, histórico de perturbações, a dinâmica do dossel e a complexidade da estrutura vertical também se refletem no padrão espacial das árvores de uma floresta (ARMESTO et al., 1986; HAASE et al., 1997; BATISTA e MAGUIRE, 1998; ANJOS et al., 1998; COOMES et al., 1999; KUULUVAINEN e ROUVINEN, 2000).

Estudar o padrão espacial das árvores que constituem o sub-bosque e dossel, assim como as relações espaciais entre árvores adultas e jovens, ao lado de estudos abordando a escala de perturbações e a heterogeneidade ambiental (HUBBELL, 1979; SCHWARZ et al., 2003), pode auxiliar a caracterizar a dinâmica de regeneração das florestas tropicais (GRAU, 2000), oferecendo subsídios para a compreensão da estrutura horizontal e vertical da floresta, e avaliar como os processos ecológicos de cada bioma interferem nos estágios de vida das árvores.

Outros processos ecológicos, como a competição interespecífica e intraespecífica (KENKEL, 1988), a herbivoria e presença de patógenos, a limitação na dispersão de sementes, a disponibilidade de nutrientes, água e luz definem o sucesso no recrutamento e na colonização do sub-bosque e dossel da floresta, a densidade das populações e de seu padrão espacial (HUBBELL, 1979; BATISTA, 1994). O ímpeto do estudo dos padrões espaciais em comunidades de plantas parte do pressuposto de que para compreendê-las, deve-se descrever e quantificar suas características espaciais e temporais e relacioná-las a outros processos como crescimento, competição, reprodução e mortalidade (ANJOS, 1998).

As principais teorias que fazem predição do padrão espacial das árvores em florestas tropicais são a de Janzen-Connell (JANZEN, 1970; CONNELL, 1971) e a de Hubbell (HUBBELL, 1979). Os autores relacionam o padrão espacial das árvores com processos ecológicos atuantes ao longo do ciclo de vida de cada árvore, revelando como os indivíduos se encontram organizados 
horizontalmente no ambiente, sendo a combinação de fatores bióticos e abióticos, que podem ajudar na compreensão da dependência espacial das espécies e do padrão de distribuição das mesmas (PEREIRA, 2005; SILVA, 2008).

Segundo a teoria da hipótese de fuga de Janzen-Connell, quanto mais distante de adultos, maiores seriam as chances de sobrevivência dos jovens. A dispersão de sementes seria, portanto, questão-chave no sucesso do estabelecimento e crescimento das novas plantas, na medida em que lança os propágulos a locais mais favoráveis. Para elucidação da regeneração, é possível obter mediante ajuste de modelos de padrões espaciais, simular estes processos, tanto dos indivíduos ingressantes e os indivíduos em mortalidade, para utilização em modelos da dinâmica da floresta (BATISTA e MAGUIRE, 1998).

Hubbell (1979), por sua vez, argumenta que padrões agregados, sobretudo em função da concentração de árvores jovens, são mais comuns em florestas tropicais do que em padrões aleatórios, como seria esperado segundo a hipótese de fuga. Segundo este autor, a própria caracterização ambiental da floresta pode levar à formação de manchas e grupos de árvores bem definidos, onde há predominância de algumas espécies, em razão de fatores ambientais, dando à floresta uma fisionomia de mosaico vegetacional (ARMESTO et al., 1986) e caracterizando, até mesmo um padrão espacial agregado em certas escalas de distâncias.

Os padrões espaciais refletem processos ecológicos implícitos, e é por esta razão que é realizado o desenvolvimento de análises estatísticas aplicadas à ecologia de plantas para poder compreender estes processos (PERRY et al., 2002). Estas análises podem indicar a existência de processos que predominam sobre a distribuição das plantas, como por exemplo: o padrão regular poderia indicar concorrência entre as espécies, ao contrário do padrão agregado que indica facilitação de agregação, porém, para a análise da interpretação dos dados, é necessário cautela, pois vários processos podem gerar o mesmo padrão espacial durante as análises estatísticas (WIEGAND e MOLONEY, 2004; PINAZO et al., 2009).

A função $\mathrm{K}$ de Ripley (caso univariado) (RIPLEY, 1977) é uma forma de caracterizar as propriedades de segunda ordem de padrões pontuais estacionários e isotrópicos e possui a vantagem de ser facilmente estimada a partir de um conjunto de dados, sem a necessidade de definição de modelos paramétricos para o padrão estudado (DIGGLE, 2003). É um método baseado em contagem e em distância, sendo necessário o conhecimento das coordenadas $(\mathrm{x}, \mathrm{y})$ de cada ponto. Esta função permite, ainda, que sejam feitas interferências sobre os valores associados a cada ponto, chamadas de marcas (caso univariado marcado). Deste modo, pode-se avaliar a correlação existente entre as marcas (entre altura ou diâmetro das árvores, por exemplo) em um processo espacial (ANJOS, 2004). Trata-se, portanto, de uma ferramenta estatística apropriada para determinar se existe agrupação, regularidade ou repulsão entre os padrões de pontos ou se simplesmente o padrão em estudo é caracterizado aleatório, cujas principais vantagens são a possibilidade de detectar o padrão espacial em diferentes escalas, simultaneamente (GETIS e FRANKLIN, 1987; BATISTA e MAGUIRE, 1998), e testar a independência espacial entre grupos de árvores quaisquer (RIPLEY, 1977; BATISTA, 1994; ANJOS et al., 1998).

Dada a importância do padrão espacial das árvores para compreensão dos processos ecológicos em florestas tropicais e a capacidade da função K de detectar padrões espaciais em diferentes escalas, este estudo teve como objetivos: (1) descrever o padrão espacial de quatro formações florestais do estado de São Paulo, sendo elas: Floresta Ombrófila Densa Submontana, Floresta Pioneira com Influência Marinha (Restinga), Floresta Estacional Semidecidual e Cerradão, (2) estudar o padrão espacial das quatro espécies de maior densidade em cada formação florestal e, nas espécies que ocorrerem em mais de uma formação, como o padrão espacial muda entre as formações, (3) descrever o padrão espacial por classes de diâmetro, analisando como este é formado a partir do padrão dos indivíduos de diferentes tamanhos.

\section{MATERIAIS E MÉTODOS}

\section{Áreas de Estudo}

Este estudo foi desenvolvido em quatro parcelas permanentes situadas em quatro Unidades de Conservação do Estado de São Paulo, localizadas no sudeste de Brasil, dentro do Projeto "Diversidade, dinâmica e conservação em florestas do Estado de São Paulo: 40 ha de parcelas permanentes", do programa Biota da Fundação de Amparo à Pesquisa do Estado de São Paulo (FAPESP). Em cada Unidade de Conservação foi montada uma parcela permanente de 10,24 ha (320 x $320 \mathrm{~m})$, subdividida 
em 256 subparcelas contíguas de $400 \mathrm{~m}^{2}$, onde todas as árvores com circunferência na altura do peito igual ou superior a $15 \mathrm{~cm}$ foram medidas, georreferenciadas e identificadas.

As árvores em cada parcela permanente foram divididas em diferentes classes de tamanho, sendo: (1) $\mathrm{d} \leq 10 \mathrm{~cm}$, (2) $10 \mathrm{~cm} \leq \mathrm{d}<20 \mathrm{~cm}$, (3) 20 $\mathrm{cm} \leq \mathrm{d}<30 \mathrm{~cm}$, (4) $30 \mathrm{~cm} \leq \mathrm{d}<40 \mathrm{~cm}$, (5) $40 \mathrm{~cm}$ $\leq \mathrm{d}<50 \mathrm{~cm},(6) \mathrm{d} \geq 50 \mathrm{~cm}$. A amplitude das classes foi a mesma para as quatro áreas, de modo a facilitar a análise e a comparação entre elas. Apenas no Cerradão, em razão do número reduzido de árvores maiores que $40 \mathrm{~cm}$ em comparação com as outras áreas, é que foram definidas cinco classes, e não seis como nas demais.

O Parque Estadual da Ilha do Cardoso, no litoral sul do Estado de São Paulo, é a maior ilha do Estado, com uma área de 22.500 ha. Possui altitudes de até $800 \mathrm{~m}$, solos do tipo podzol hidromórfico, a temperatura varia de $19{ }^{\circ} \mathrm{C}$ a $27^{\circ} \mathrm{C}$ e precipitação anual de 1.800 a $2.000 \mathrm{~mm}$, e clima classificado no sistema de Köppen como Cfa (mesotérmico úmido). Predominando assim, a Formação Pioneira com Influência Marinha, conhecida por Restinga (SAMPAIO, 2003).

O Parque Estadual de Carlos Botelho, na região sul do Estado, possui uma área superior a 37.000 ha. A temperatura varia de $18^{\circ} \mathrm{C}$ a $22^{\circ} \mathrm{C} \mathrm{com}$ precipitação anual de aproximadamente $1.600 \mathrm{~mm}$. O clima caracteriza-se como mesotérmico úmido, o solo apresenta elevados teores de matéria orgânica e alumínio, baixos teores de cálcio, magnésio, fósforo e potássio, e acidez elevada. A altitude varia de 30 a $1.003 \mathrm{~m}$, sendo que, a parcela permanente encontra-se a $150 \mathrm{~m}$ acima do nível do mar. Tratase de um remanescente bem preservado de Floresta Ombrófila Densa Submontana, dentro dos domínios da Mata Atlântica (DIAS, 1993).

A Estação Ecológica de Assis, com uma área de aproximadamente 1.300 ha, localiza-se na região oeste de São Paulo, com fisionomia de cerrado lato sensu. A altitude varia de 520 e $590 \mathrm{~m}$, a precipitação anual fica em torno de $1.400 \mathrm{~mm}$ e o clima é Cwa (mesotérmico), segundo a classificação de Köppen (CAPRETZ, 2004).

A Estação Ecológica de Caetetus constitui uma das maiores áreas contínuas representativas de Floresta Estacional Semidecidual, com aproximadamente 2.100 ha, com trechos em excelente estado de conservação (FRANCO, 2002). A altitude varia de 500 a 680 m, os solos são classificados como latossolos e podzólicos abruptos nas vertentes, a precipitação anual média é de 1.400 mm e o clima é definido como Cwa (mesotérmico) de acordo com a classificação de Köppen (CAPRETZ, 2004).

\section{Função K de Ripley}

A função $\mathrm{K}$ é capaz de analisar o padrão espacial dando ênfase também na interação entre espécies em processos de dinâmica florestal como sobrevivência, crescimento e competição (CAPRETZ et al., 2003). A função computa todas as distâncias entre as árvores em um mapa para investigar seu padrão, onde se constrói um círculo de raio (s) centrado em cada árvore, e realiza-se a contagem dos vizinhos presentes dentro da área deste círculo (HAASE, 1995; ANJOS et al., 1998; KUULUVAINEN e ROUVINEN, 2000). Variando o raio (s) é possível detectar o padrão espacial em diferentes escalas, sendo esta flexibilidade em relação à escala de distâncias o que difere substancialmente de outras ferramentas também usadas.

Para a função K de Ripley, a hipótese nula é de Completa Aleatoriedade Espacial (CAE), para função univariada (BATISTA, 1994). Para este estudo, a CAE foi testada através de envelopes de confiança construídos através 1.000 simulações Montecarlo, produzindo envelopes de confiança de $99 \%$. A análise da CAE é feita de forma gráfica para facilitar a visualização dos desvios em relação à hipótese nula (RIPLEY, 1979). Se os valores observados estiverem dentro dos envelopes construídos, o padrão espacial é aleatório e; para valores fora dos envelopes rejeita-se a hipótese nula e se os valores forem positivos o padrão é agregado, e se forem negativos, o padrão é regular.

Para o cálculo da Função K foi empregado o estimador da função com a correção proposta por Ripley baseado na correção isotrópica de bordadura segundo a fórmula (1) (RIPLEY, 1977).

$$
\widehat{K}(s)=\frac{1}{\lambda n} \sum_{i=}^{n} \sum_{\substack{j=1 \\ i \neq j}}^{n} w_{I}^{-1}\left(x_{i}, x_{j}\right) I\left(\left\|x_{i}-x_{j}\right\|<s\right)
$$

onde: $n$ é o número de árvores na região de estudo; $x_{i}$ e $x_{j}$ são as coordenadas dos pontos do mapa; $\left\|x_{i}-x_{j}\right\|$ é a distância euclidiana entre as localizações $x_{i} \mathrm{e} x ; j$ é m vetor arbitrário de distâncias; $\hat{\lambda}=n /\|A\|$ é o número de árvores dividido pela área da região de estudos, sendo um estimador não viciado da intensidade do processo; $w_{I}\left(x_{i}, x_{j}\right)$ é a função de correção isotrópica de bordadura, a qual representa a proporção da 
circunferência com centro em $x_{i}$ e com raio $\left\|x_{i}-x_{j}\right\|$ que está fora da região de estudo; essa função é definida para qualquer polígono convexo; $I(U)$ é uma função indicadora que assume o valor 1 (um) sempre que a condição $U$ for verdadeira, e zero quando a condição for falsa.

Em regiões de estudo retangulares, o estimador de Ripley é um estimador não viciado da função $\mathrm{K}$ para distâncias inferiores à metade do menor lado do retângulo (DIGGLE, 1983), por esse motivo a escala de distâncias deste estudo vai de 1 a $160 \mathrm{~m}$, uma vez que cada parcela permanente tem 320 x $320 \mathrm{~m}$. Os resultados são transformados na função $L(s)$ para facilitar a visualização sendo elaborado um gráfico da função $L(s)$, segundo a fórmula (2) relacionada com a distância $s$.

$$
\widehat{L(s)}=\sqrt{\widehat{K(s)} / \pi}-s
$$

\section{RESULTADOS E DISCUSSÃO}

\section{Caracterização das Formações Florestais}

No inventário florestal foram levantadas 22.917 árvores em Assis (2.238 árv.ha ${ }^{-1}$ ), 12.781 em Caetetus (1.248 árv.ha $\left.{ }^{-1}\right), 10.629$ em Carlos Botelho (1.038 árv.ha-1) e 16.949 na Ilha do Cardoso (1.655 árv.ha-1 ${ }^{-1}$. A função $\mathrm{K}$ de Ripley calculada para cada formação florestal e seus respectivos envelopes de confiança são mostrados na Figura 1, onde, a linha horizontal a partir do valor $L(s)=0$ serve como referência para os envelopes de confiança (linhas tracejadas) para os modelos de Completa Aleatoriedade Espacial. A CAE foi rejeitada em todas as quatro áreas de estudo, embora o padrão espacial seja diferente entre elas (Figura 1). Diferentes níveis de agregação foram observados ao longo da escala de distâncias nos quatro casos, porém, em algumas áreas, sobretudo na Floresta Estacional, este comportamento foi restrito apenas para a primeira classe de tamanho (árvores com $\mathrm{d} \leq 10 \mathrm{~cm}$ ). Estes indivíduos jovens provavelmente apresentaram maior nível de agregação por estarem em processo de recrutamento. Neste processo, as plantas jovens sofreram o aumento da taxa de competição intra e interespecífica, consequentemente, as taxas de mortalidade aumentaram, selecionando as espécies no habitat, confirmando a Teoria de Janzen e Connell. Assim, os indivíduos acabam caracterizando-se um padrão aleatório.

Quando colocadas na mesma figura, as curvas do padrão espacial observado, nas quatro áreas, verificou-se que as diferenças entre elas tornaram-se ainda mais evidentes. $\mathrm{O}$ padrão observado na Floresta Ombrófila foi bem diferente dos demais, comportamento devido ao caráter fortemente agregado do padrão espacial das árvores desta formação florestal. Esta foi a única área onde o padrão agregado foi detectado para todas as distâncias. Fica evidente também, nesta figura, a semelhança entre o padrão espacial do Cerradão e da Restinga. Souza et al. (2010), estudando métodos geoestatísticos capazes de captar e descrever a estrutura espacial para estas mesmas áreas, verificaram que a estrutura espacial foi distinta entre estratos, entre as formações florestais e mais visíveis nos indivíduos do sub-bosque. Podendo sugerir que as árvores de sub-bosque apresentam um padrão de dependência espacial mais pronunciado do que o das árvores de dossel.

Para as árvores do Cerradão, a hipótese de aleatoriedade foi rejeitada a partir de distâncias menores, até aproximadamente $120 \mathrm{~m}$. Os valores de $L(s)$ foram crescentes até $90 \mathrm{~m}$, a partir de onde a curva assume um comportamento decrescente. Isto significa que o tamanho dos agrupamentos dentro da parcela permanente varia até aproximadamente 90 m, e que após esta escala os agrupamentos são muito menos nítidos, mas somente após a marca de $120 \mathrm{~m}$ é que se pode dizer que não há agrupamentos observados.

$\mathrm{Na}$ Floresta Estacional a hipótese de aleatoriedade foi rejeitada apenas até $45 \mathrm{~m}$ de distância. O padrão espacial predominante na Floresta Estacional foi, portanto, o padrão aleatório. Certa tendência em direção à regularidade foi observada, embora não tenha sido significativa, uma vez que a curva manteve-se dentro dos envelopes de confiança.

Como foi descrito anteriormente, o padrão agregado foi observado em todas as escalas na parcela permanente na Floresta Ombrófila. Não é possível diferenciar claramente em quais escalas os agrupamentos foram mais nítidos, resultando em um padrão de agregação complexo. O padrão agregado é comum em florestas tropicais, especialmente em razão do grande de número de árvores da mesma espécie na sua vizinhança (HUBBELL, 1979). Ao estudar vegetação da Ilha de Barro Colorado, no Panamá, encontraram-se padrões agregados das árvores, especialmente em função de um elevado recrutamento na vizinhança das árvores parentais (CONDIT et al., 1992). 
Embora seja possível afirmar que as árvores nas quatro formações florestais estudadas apresentam padrão agregado, diferenças no comportamento da curva da Função K merecem maior atenção. Ambientes heterogêneos correspondem a níveis elevados de agregação, enquanto áreas mais homogêneas apresentam níveis mais baixos (CONDIT et al., 2000). Níveis de agregação são atribuídos principalmente à disponibilidade de recursos (COLLINS e KLAHR, 1991; GRAU, 2000), condições microclimáticas específicas e reduzida capacidade de dispersão. De modo oposto, a intensa competição por recursos pode levar a padrões regulares (HAASE, 1995). A disponibilidade de recursos refere-se principalmente a nutrientes e água no solo (COLLINS e KLAHR,
1991). Condições microclimáticas favoráveis surgem principalmente em razão da estrutura do dossel da floresta, propiciando filtragem de luz e maior influência do vento (LEEMANS, 1991; HOULE, 1992), ou mesmo devido a um relevo acidentado (CONDIT et al., 2000; SCHWARZ et al., 2003).

\section{Caracterização por classes de diâmetro}

A distribuição de classes de diâmetro por formação florestal foi semelhante entre elas, exponencial negativa, mostrando uma progressiva diminuição do número de indivíduos conforme o aumento do tamanho.

Uma comparação entre a estrutura diamétrica das quatro parcelas permanentes fica mais
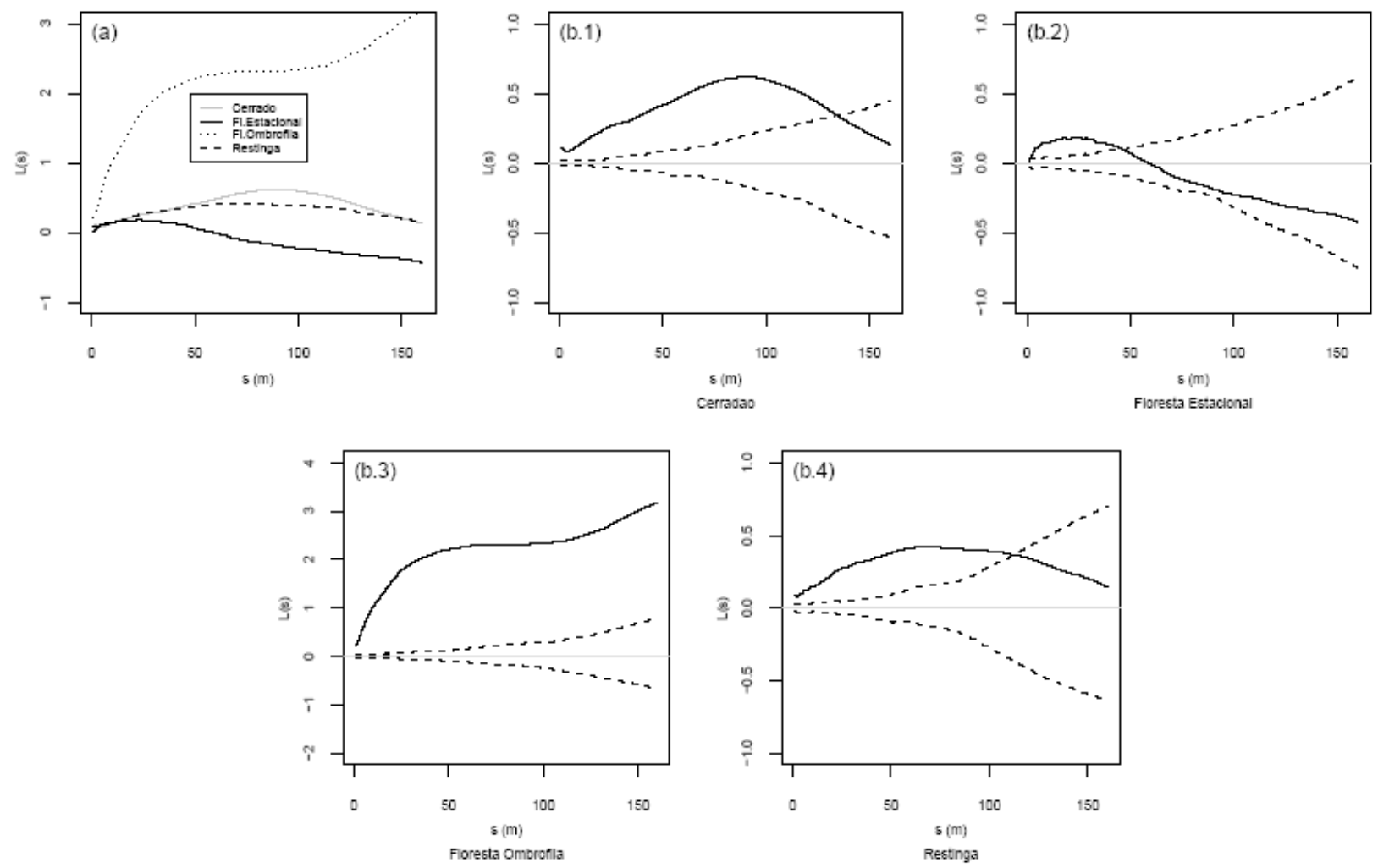

FIGURA 1: Padrão espacial observado para as árvores em cada parcela permanente: a) Comparação entre o padrão das quatro áreas. b) Padrão espacial observado para cada fisionomia estudada do Estado de São Paulo: b.1) Cerradão, b.2) Floresta Estacional, b.3) Floresta Ombrófila, b.4) Restinga. As linhas tracejadas indicam os envelopes de confiança pelas simulações do Método Montecarlo a 99 \%, para a Completa Aleatoriedade Espacial (CAE). As linhas contínuas demonstram o ajuste pela Função K de Ripley transformado $(L(s))$.

FIGURE 1: Tree's spatial pattern observed in each permanent plot: a) comparison among the pattern in the four areas. b) Spatial pattern observed for each studied physiognomy in Sao Paulo State: b.1) 'Cerradão', b.2) Seasonal Forest, b.3) Ombrophilous Forest, b.4) Forest of 'Restinga'. The dashed lines represent the confidence envelopes (99\%) by Montecarlo Method simulations for a complete spatial randomness (CAE). The solid lines demonstrate the adjustment for transformed Ripley's K function $(L(s))$. 
clara através da figura 2, onde estão representadas as suas classes definidas anteriormente. Os quatro histogramas foram muito semelhantes, mostrando uma progressiva diminuição do número de indivíduos conforme o aumento do tamanho.

Padrões agregados foram encontrados nas classes de diâmetro menor, e padrões aleatórios para as classes de diâmetro maior, em todas as áreas deste estudo. Outros estudos obtiveram observações semelhantes (HAASE et al., 1997; BUSING, 1998; BAROT et al., 1999; GRAU, 2000; EDMAN e JONSSON, 2001). Uma das formas de se testar a hipótese de fuga de Janzen-Connell (JANZEN, 1970; CONNELL, 1978) é avaliar o padrão espacial das árvores jovens, adultas e senescentes, e a relação de independência espacial entre as classes (BAROT et al., 1999; CONDIT et al., 2000). Ainda segundo os autores, a passagem de um padrão agregado de jovens para um padrão aleatório de adultos ocorre principalmente em função da mortalidade, dependendo da densidade. Padrões agregados de árvores jovens em escalas menores que $15 \mathrm{~m}$ são fortes indícios da influência de clareiras produzidas pela queda de árvores do dossel na regeneração da floresta (GRAU, 2000). Plantas em diferentes estágios de vida possuem diferentes necessidades e, em função disso, apresentam padrões espaciais distintos. Condições de sombreamento e filtragem de luz, assim como espaços disponíveis no dossel da floresta, são algumas características ambientais importantes para o desenvolvimento de árvores jovens (BATISTA, 1994; BAROT et al., 1999).

As árvores do Cerradão, divididas segundo seu tamanho, e as análises do padrão espacial em cada classe são mostradas na Figura 3. Padrões agregados foram observados em árvores com $\mathrm{d} \leq 10 \mathrm{~cm}$ e $10 \mathrm{~cm} \leq \mathrm{d}<20 \mathrm{~cm}$, em distâncias próximas a $130 \mathrm{~m}$. Para todas as demais classes a CAE foi aceita. Na classe 5 (árvores a partir de 40 $\mathrm{cm}$ ) houve um pequeno desvio em relação à CAE, em uma escala de aproximadamente $105 \mathrm{~m}$. De fato, há uma tendência de agregação para esta última classe a partir de $75 \mathrm{~m}$.

O padrão espacial observado para as árvores em cada classe de tamanho na Floresta Estacional é apresentado na Figura 4.

O padrão espacial observado para árvores com diâmetro menor que $10 \mathrm{~cm}$ foi agregado até $50 \mathrm{~m}$, aleatório de $50 \mathrm{~m}$ a $110 \mathrm{~m}$ e regular a partir deste ponto. Para as demais classes, o padrão
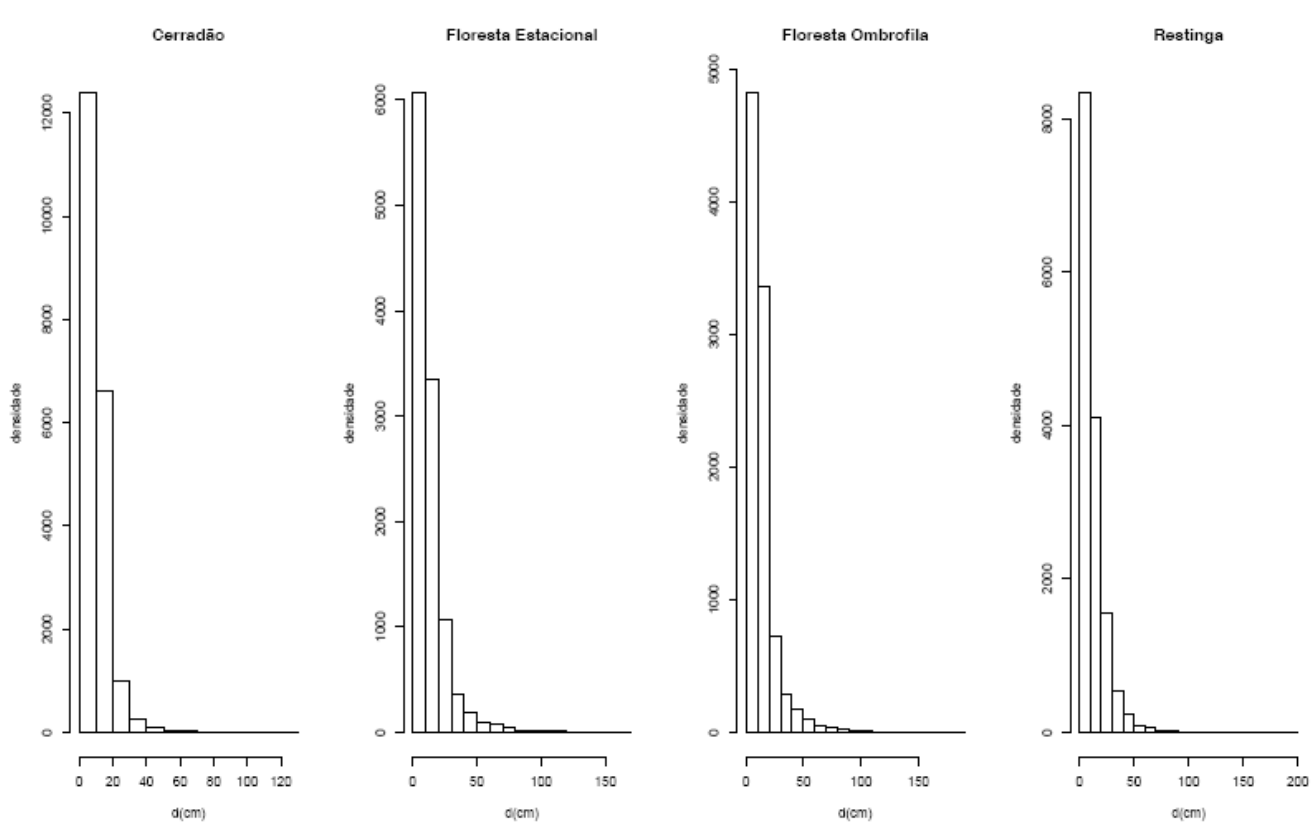

FIGURA 2: Histogramas segundo as classes de diâmetro das árvores de cada parcela permanente nas quatro áreas de estudo (Cerradão, Floresta Estacional, Floresta Ombrófila e Restinga) - São Paulo, Brasil.

FIGURE 2: Histograms according to the tree's diameter classes found in each permanent plot of each study area ('Cerradão', Seasonal Forest, Ombrophilous Forest and Forest of 'Restinga') - São Paulo, Brazil. 

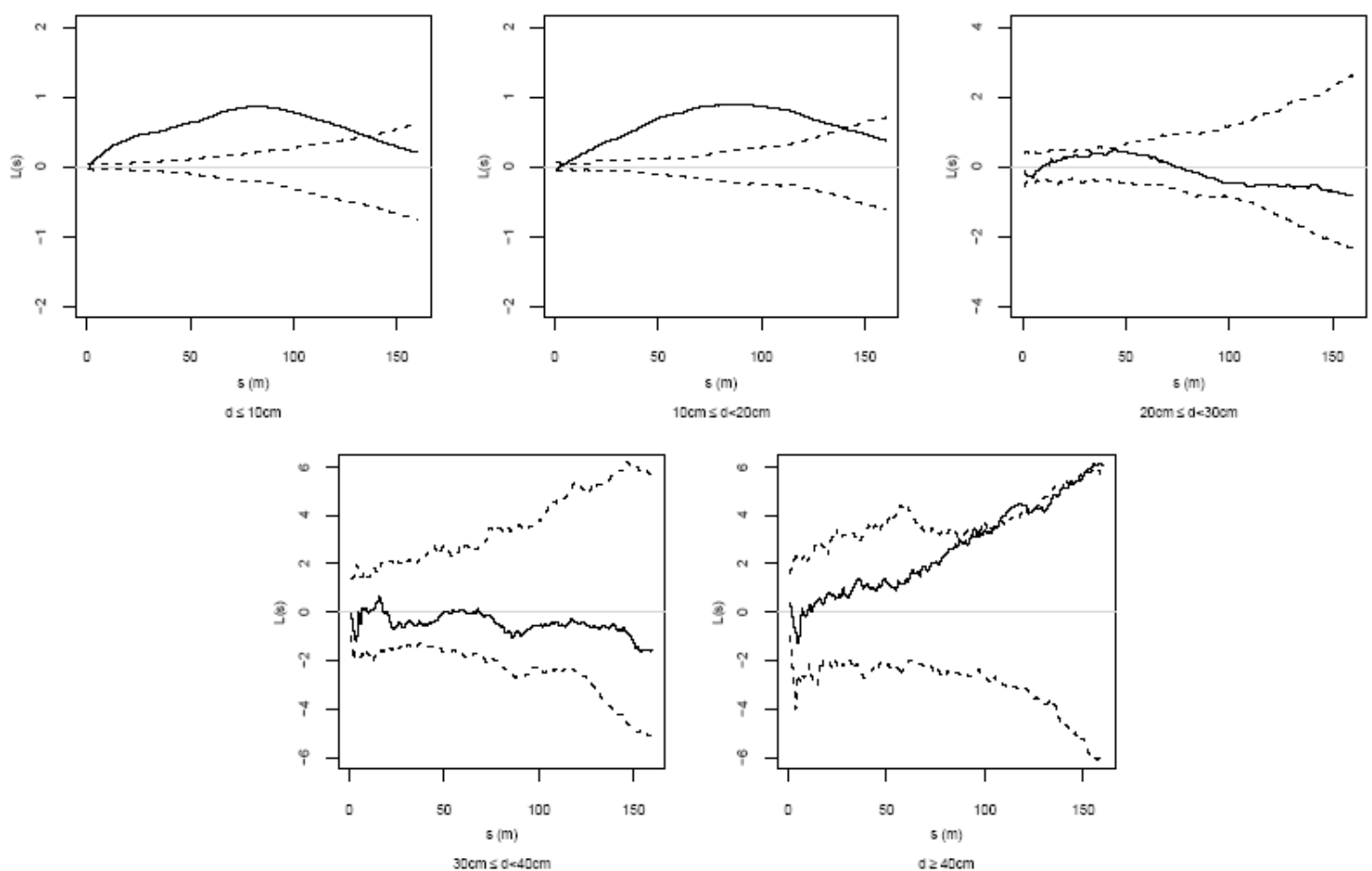

FIGURA 3: Análise do padrão espacial das árvores, segundo classes de diâmetro no Cerradão, na Estação Ecológica de Assis, São Paulo, Brasil. As linhas tracejadas indicam os envelopes de confiança pelas simulações do Método Montecarlo a 99 \%, para a Completa Aleatoriedade Espacial (CAE). As linhas contínuas demonstram o ajuste pela Função K de Ripley transformado $(L(s))$.

FIGURE 3: Analysis of tree's spatial patterns according to diameter classes in 'Cerradão', Ecological Station Assis, São Paulo state, Brazil. Dashed lines indicate the confidence envelopes ( $99 \%$ ) by Montecarlo Method simulations for a complete spatial randomness (CAE). Solid lines demonstrate the adjustment for transformed Ripley's K function $(L(s))$.
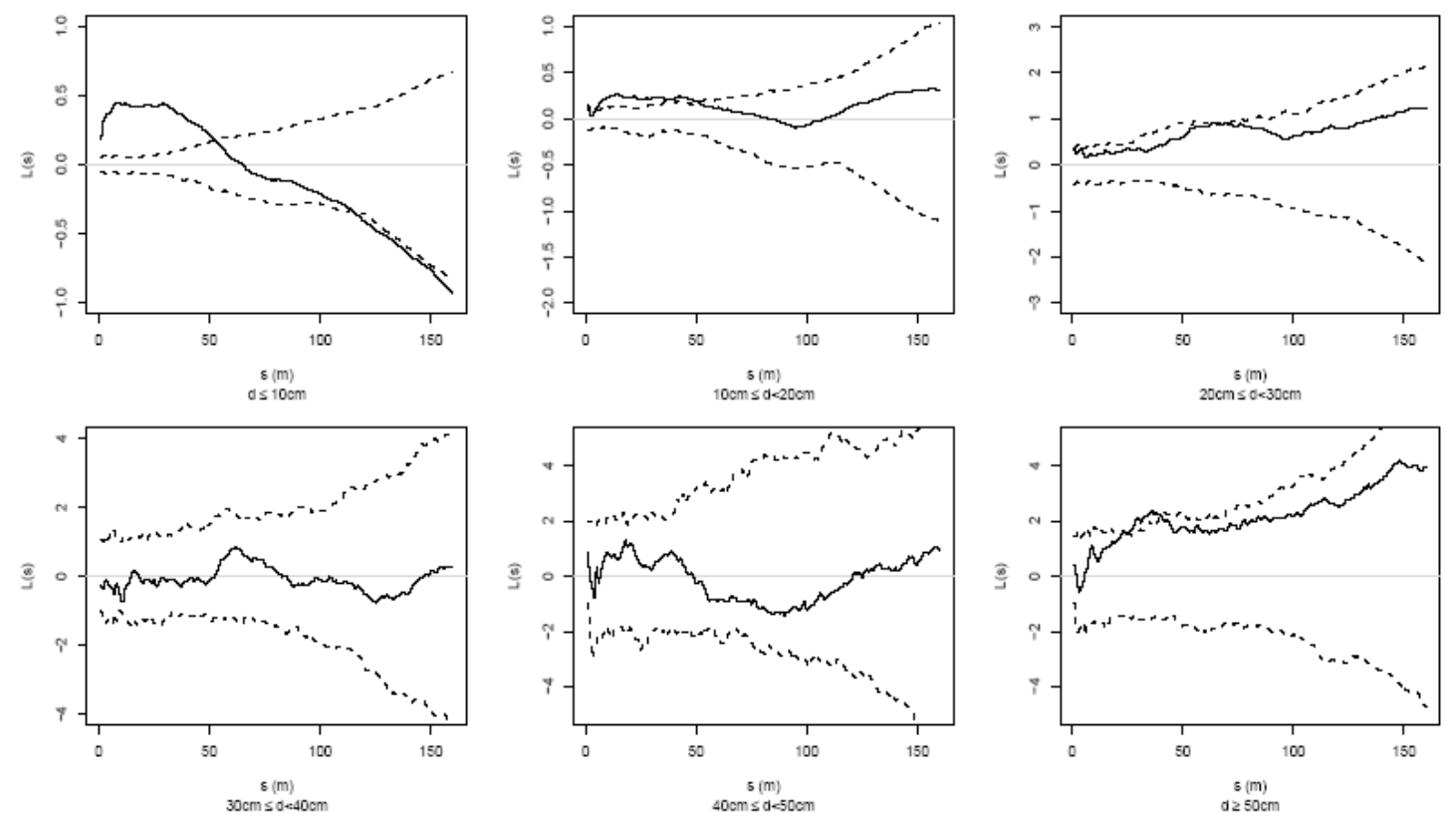

FIGURA 4: Análise do padrão espacial das árvores, segundo as classes de diâmetro, na Floresta Estacional Semidecidual da Estação Ecológica de Caetetus, São Paulo, Brasil. As linhas tracejadas indicam os envelopes de confiança pelas simulações do Método Montecarlo a 99 \%, para a Completa Aleatoriedade Espacial (CAE). As linhas contínuas demonstram o ajuste pela Função K de Ripley transformado $(L(s))$.

FIGURE 4: Analysis of tree's spatial pattern according to diameter classes in Semi-deciduous Seasonal Forest at the Ecological Station Caetetus, Sao Paulo, Brazil. Dashed lines indicate the confidence envelopes (99\%) by Montecarlo Method simulations for a complete spatial randomness $(L(s))$. Solid lines demonstrate the adjustment for transformed Ripley's $\mathrm{K}$ function $(L(s))$. 
predominante foi o aleatório. Apenas em duas classes houve pequenos desvios em relação à CAE: na classe $10 \mathrm{~cm} \leq \mathrm{d}<20 \mathrm{~cm}$, até $50 \mathrm{~m}$, e na classe $\mathrm{d} \geq 50 \mathrm{~cm}$, entre 30 e $50 \mathrm{~m}$. O formato da curva na classe $\mathrm{d} \geq 50 \mathrm{~cm}$ permite supor que as árvores maiores tenham grande tendência à agregação, embora sem significância estatística.

As árvores da Floresta Ombrófila, divididas segundo seu diâmetro e o padrão espacial correspondente, são mostrados na Figura 5.

No mapa das árvores foi possível identificar pelo menos duas grandes clareiras na parcela permanente. As mesmas foram visíveis nos mapas de todas as classes de diâmetro, sendo assim, foi possível compreender que os efeitos destas duas áreas foram determinantes para o seu padrão espacial. Foi observado um padrão predominantemente agregado para as três primeiras classes na parcela permanente na Floresta Ombrófila, enquanto que as três últimas apresentaram padrão aleatório. $\mathrm{O}$ padrão da primeira classe de diâmetro foi muito semelhante ao padrão geral na área (Figura 1), e a agregação foi significativa em todas as escalas para as duas primeiras classes. As três últimas classes apresentaram desvios em relação ao modelo de Completa Aleatoriedade Espacial em distâncias entre 30 e $100 \mathrm{~m}$.

O padrão espacial observado para cada classe de diâmetro na Restinga (Figura 6) foi similar ao encontrado nas outras áreas de estudo: padrão agregado para as primeiras classes e padrão aleatório para as últimas. O modelo de Completa Aleatoriedade Espacial foi rejeitado para as classes $\mathrm{d} \leq 10 \mathrm{~cm}$ e $10 \mathrm{~cm} \leq \mathrm{d}<20 \mathrm{~cm}$, e aceito para as demais.

\section{Caracterização das espécies representativas das formações florestais}

Foi realizada uma análise do padrão espacial em cada parcela permanente tomando como base as espécies de maior densidade em cada formação, segundo a Tabela 1.
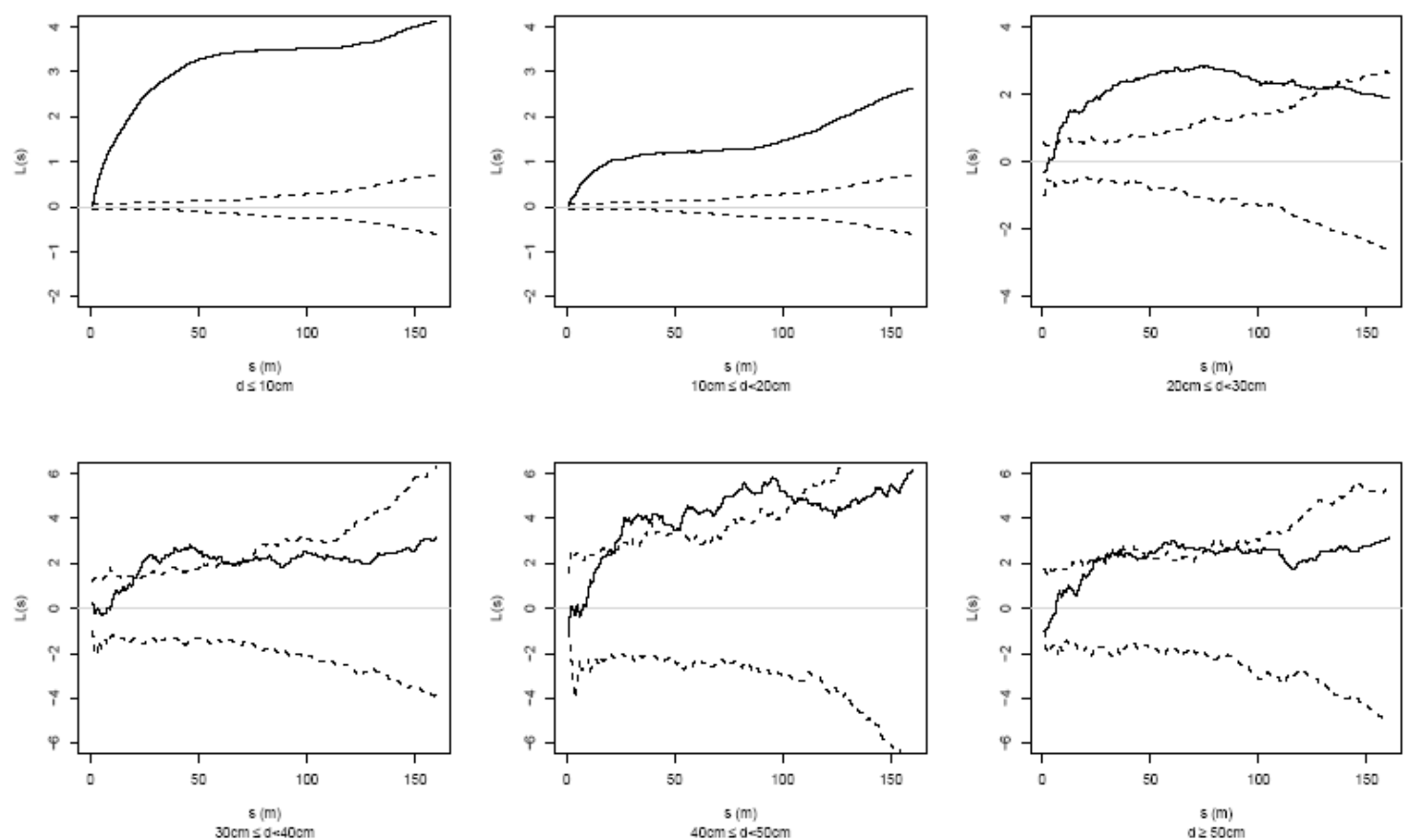

FIGURA 5: Análise do padrão espacial das árvores, segundo as classes de diâmetro, na Floresta Ombrófila do Parque Estadual de Carlos Botelho, São Paulo, Brasil. As linhas tracejadas indicam os envelopes de confiança pelas simulações do Método Montecarlo a 99 \%, para a Completa Aleatoriedade Espacial (CAE). As linhas contínuas demonstram o ajuste pela Função K de Ripley transformado $(L(s))$.

FIGURE 5: Analysis of tree's spatial pattern according to diameter classes in Ombrophilous Forest of Carlos Botelho State Park, Sao Paulo, Brazil. Dashed lines represent the confidence envelopes (99\%) by Montecarlo method simulations for a complete spatial randomness (CAE). Solid lines demonstrate the adjustment for transformed Ripley's K function $(L(s))$. 

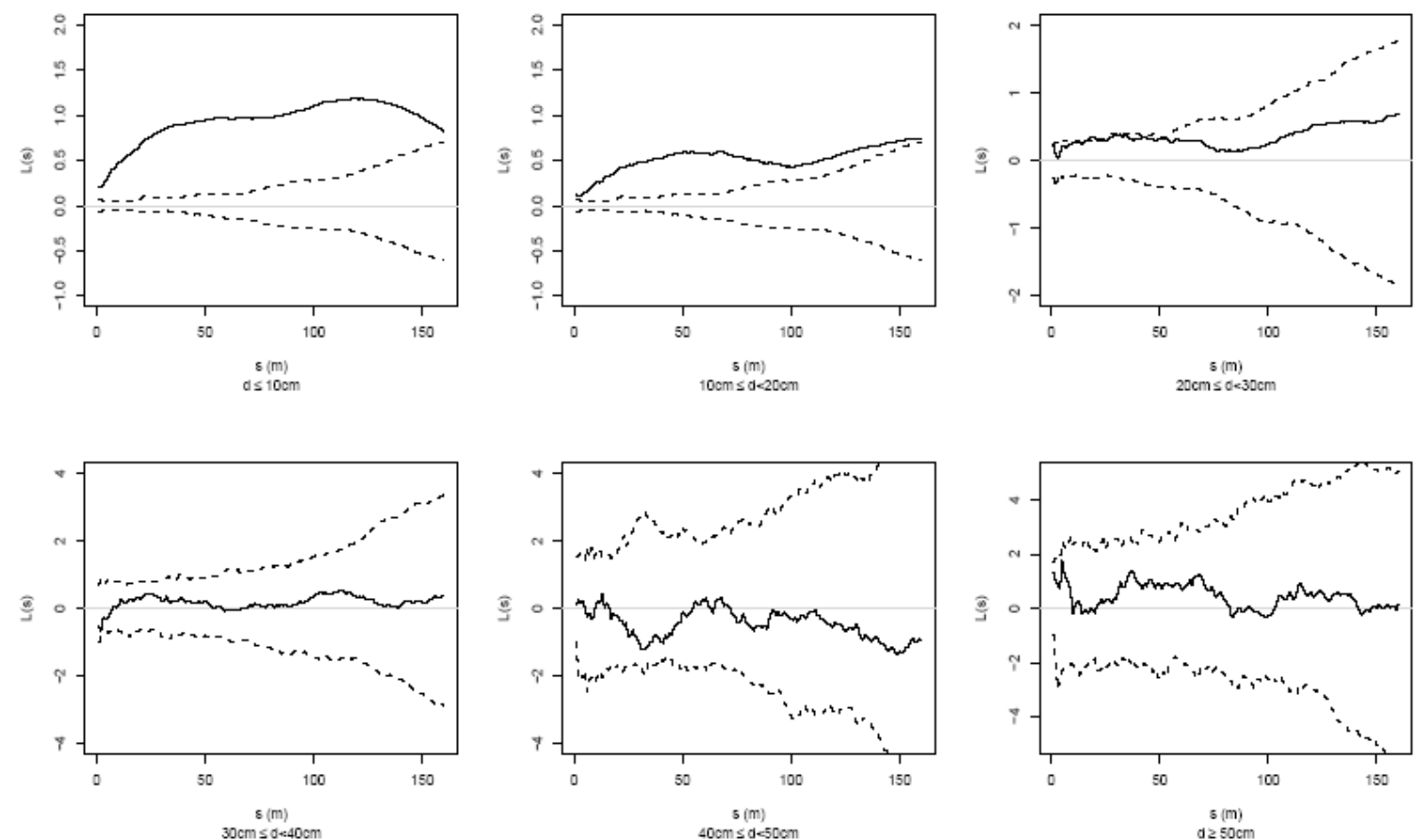

FIGURA 6: Análise do padrão espacial das árvores segundo as classes de diâmetro na Restinga do Parque Estadual da Ilha do Cardoso, São Paulo, Brasil. As linhas tracejadas indicam os envelopes de confiança pelas simulações do Método Montecarlo a 99 \%, para a Completa Aleatoriedade Espacial (CAE). As linhas contínuas demonstram o ajuste pela Função K de Ripley transformado $(L(s))$.

FIGURE 6: Analysis of tree's spatial pattern according to diameter classes at Ilha do Cardoso State Park of Restinga, São Paulo, Brazil. Dashed lines represent the confidence envelopes (99\%) by Montecarlo method simulations for a complete spatial randomness (CAE). Solid lines demonstrate the adjustment for transformed Ripley's K function $(L(s))$.

TABELA 1: Espécies de maior densidade nas Unidades de Conservação estudadas, São Paulo, Brasil.

TABLE 1: Species of higher density at the studied Conservation Units, São Paulo, Brazil.

\begin{tabular}{llc}
\hline Formação Florestal & \multicolumn{1}{c}{ Espécie } & $\mathrm{N}^{\circ}$ de Indivíduos (ha) \\
\hline \multirow{4}{*}{ Cerradão } & Copaifera langsdorffi Desf. & 346 \\
& Vochysia tucanorum Mart. & 209 \\
& Xylopia aromatica (Lam.) Mart & 156 \\
& Ocotea corymbosa (Meisn.) Mez & 145 \\
\hline \multirow{3}{*}{ Floresta Estacional } & Metrodorea nigra A.St. - Hil. & 394 \\
Semidecidual & Trichilia claussenii C.DC. & 58 \\
& Aspidosperma polyneuron Müll. Arg. & 57 \\
& Ocotea indecora (Schott) Mez. & 57 \\
\hline \multirow{5}{*}{ Floresta Ombrófila } & Euterpe edulis Mart. & 204 \\
Densa & Guapira opposita Vell. & 34 \\
& Garcinia gardneriana (Planchon et Triana) Zappi & 24 \\
& Bathysa meridionalis L.B.Sm. \& Downs & 19 \\
\hline \multirow{5}{*}{ Restinga } & Euterpe edulis Mart. & 266 \\
& Xylopia langsdorffiana A. St.,Hil \& Tul & 84 \\
& Amaioua intermedia Mart. & 68 \\
& Andira anthelmia (Vell.) JF Macbr. & 50 \\
\hline
\end{tabular}




\section{Cerradão}

Foram observados níveis de agregação para as quatro espécies na Estação Ecológica de Assis, em todas as escalas, como apresentado na Figura $7 \mathrm{a}$.

É relevante ressaltar que as quatro espécies com maior densidade destacam-se das demais, de modo que a soma dos seus indivíduos corresponde a, aproximadamente, $38 \%$ das árvores da parcela permanente. Desvios em relação à $\mathrm{CAE}$ foram observados para todas as populações estudadas, embora sejam evidentes diferenças entre elas. A função K de Ripley salientou a semelhança entre o padrão espacial de Copaifera langsdorffii e Ocotea corymbosa. Nos dois casos a curva da função $\mathrm{K}$ mostrou um comportamento bem semelhante, com um pico evidente na marca de $100 \mathrm{~m}$ de distância. Esse padrão de agregação pode ser interpretado como um perfil de agrupamentos evidentes até distâncias de $100 \mathrm{~m}$, uma vez que a função, que é cumulativa, encontra cada vez mais indivíduos até esta escala. Após esta marca, a relativa ausência de indivíduos produz a queda na curva. Comportamento semelhante a este foi encontrado por Demelas (2007) estudando a distribuição espacial da Copaifera langsdorffii em uma mata de galeria no Mato Grosso. Ele encontrou uma tendência à desagregação dos indivíduos com o passar da idade. Verificou também, que as distâncias entre indivíduos jovens e adultos mais frequentes foram entre 40 e $45 \mathrm{~m}$ e a distância média entre adultos foi maior que $80 \mathrm{~m}$.

Performance similar também foi observado para Vochysia tucanorum, embora em outra escala, e com outra intensidade. Com relação à Xylopia aromatica, embora o padrão agrupado esteja claro, o perfil de distribuição desta espécie é mais complexo. Esta espécie é típica do sub-bosque desta formação florestal. Como não há picos evidentes, e a curva da função tem um comportamento visivelmente crescente até o fim da escala adotada no estudo, não é possível identificar em quais escalas os grupos são mais evidentes.

No Cerradão, as quatro espécies de maior densidade apresentaram características comuns: todas são heliófitas, e todas apresentaram padrões agregados em todas as escalas. O comportamento da curva da Função K de Ripley foi bastante semelhante para Ocotea corymbosa, Copaifera langsdorffii e Vochysia tucanorum, estas três espécies integram o dossel do Cerradão. A semelhança no padrão espacial das três espécies de dossel permite concluir que elas são responsáveis pela configuração espacial do topo do Cerradão.

\section{Floresta Estacional}

O padrão espacial observado para as quatro espécies em Caetetus é apresentado na Figura $7 \mathrm{~b}$. A espécie Metrodorea nigra concentra, sozinha, cerca de $33 \%$ das árvores encontradas nesta parcela permanente. A dominância dessa espécie fica ainda mais evidente quando se compara o número de indivíduos encontrados dela com o das demais espécies selecionadas neste estudo (Tabela 1).

O padrão espacial de Metrodorea nigra foi predominantemente aleatório, sobretudo a partir de uma escala de distâncias de $50 \mathrm{~m}$. A espécie, portanto, apresentou tendência de agrupamento apenas em distâncias menores. Em contrapartida, o padrão de Trichilia claussenii foi agregado, sendo que, a aleatoriedade foi rejeitada para todas as escalas. Para esta espécie, a função K de Ripley apontou grupos bem definidos, especialmente até a escala de $50 \mathrm{~m}$. Na espécie Aspidosperma polyneuron a aleatoriedade foi rejeitada na escala entre 5 e $75 \mathrm{~m}$, nas demais escalas o padrão predominante foi o aleatório. Um comportamento ligeiramente semelhante foi observado para Ocotea indecora, entre as escalas de 5 e $110 \mathrm{~m}$.

Na Floresta Estacional, duas espécies, entre as quatro de maior densidade, são reconhecidamente perenifólias: Metrodorea nigra e Aspidosperma polyneuron, embora a primeira seja espécie típica do sub-bosque, e a segunda componente do dossel. A grande densidade de Metrodorea nigra certamente contribui para a caracterização do padrão espacial da formação como um todo, uma vez que o padrão espacial observado para a espécie se assemelha muito ao padrão espacial da comunidade.

Pinazo et al. (2009) ressaltam que, quando estudado o padrão da análise espacial da regeneração, é possível encontrar agrupamentos de $30 \mathrm{~m}$ de diâmetro, o que significa que esta espécie regenera-se de forma abundante quando se encontra em condições particulares. Esta característica de agrupamento da espécie foi observada também por Fonseca et al. (2004).

\section{Floresta Ombrófila}

O padrão espacial observado para as quatro espécies coletadas no Parque Estadual de Carlos Botelho é mostrado na Figura 7c. O palmiteiro Euterpe edulis foi a espécie de maior densidade com cerca de $20 \%$ do número total de árvores encontradas, e o padrão espacial desta espécie foi agregado em todas as escalas. Agrupamentos definidos de até $25 \mathrm{~m}$ foram identificados, embora 
agrupamentos de diversos outros tamanhos ocorram em todas as escalas restantes. Tanto para Bathysa merdionalis quanto para Garcinia gardneriana, a CAE foi rejeitada. De fato, o padrão observado para ambas é muito semelhante, onde as curvas apresentam picos evidentes em torno de $40 \mathrm{~m}$, para em seguida experimentar certa queda. Novamente, a interpretação destes dados sugere a presença de grupos de tamanho correspondente a esta distância. Para as demais escalas os grupos ainda existem, (a)

\section{Copaifera langsdorff}

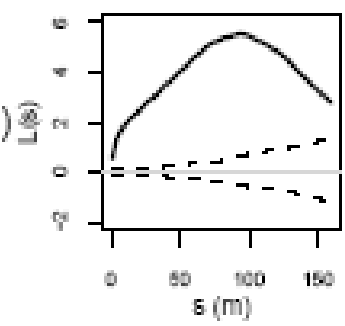

Metrodorea nigra

(b)

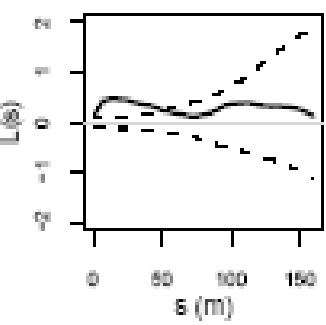

Euterpe edu's

(c)

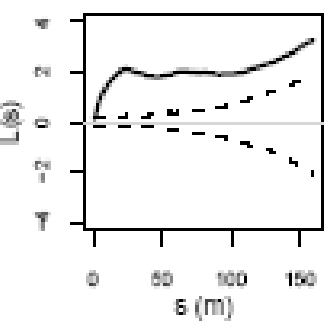

Euterpe edul's

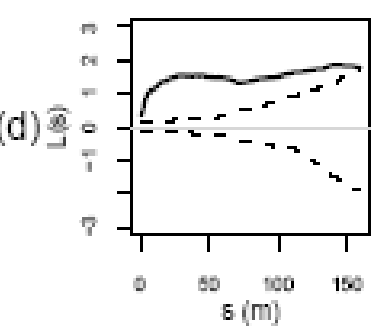

Ocotea corymbosa

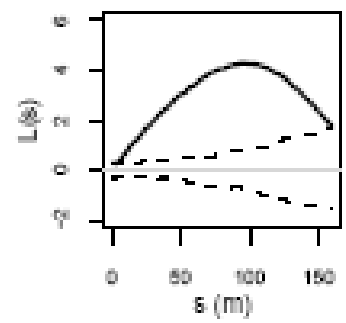

Trichilia claussenii

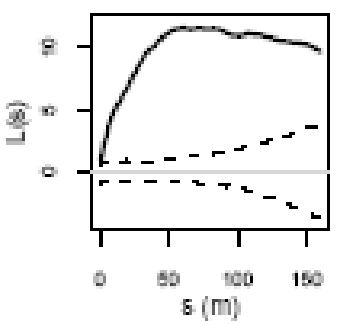

Bathysa meridionalis

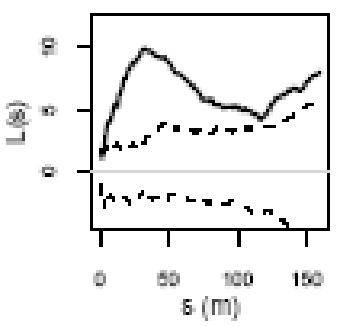

Xylopia langsdorffiana

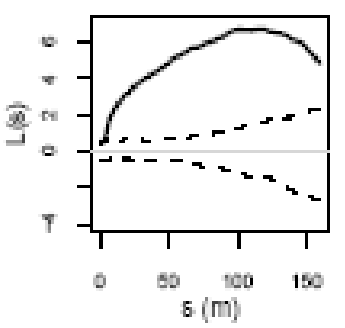

Xlopia aromatica

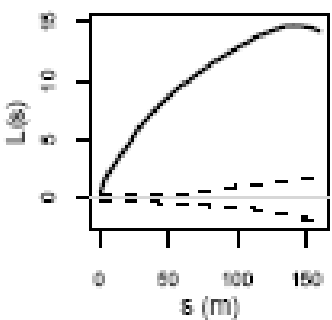

Aspidosperma polyneuron

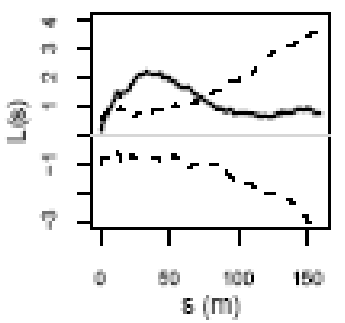

Garcinia gardineriana

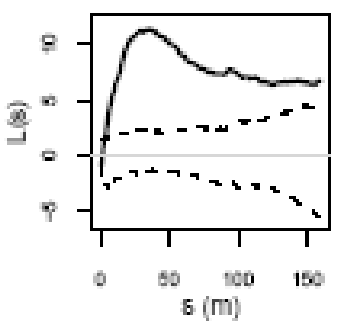

Amaioua intermedia

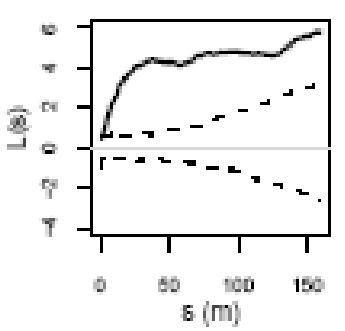

Vochysia tucanorum

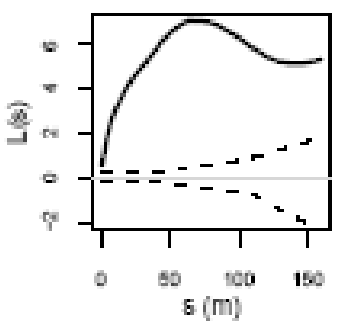

Ocotea indecora

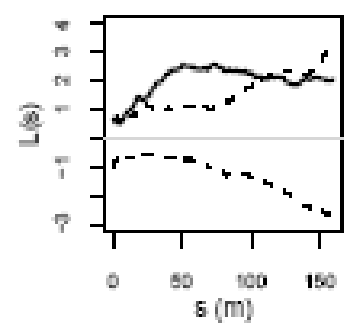

Guapira opposita

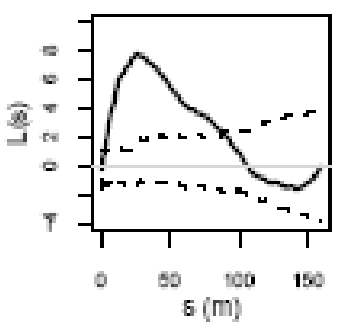

Andira anthelmia

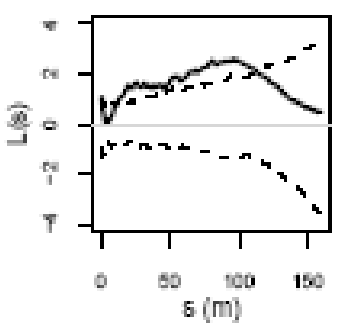

FIGURA 7: Padrão espacial observado para as espécies de maior densidade no (a) Cerradão, (b) Floresta Estacional, (c) Floresta Ombrófila e (d) Restinga em São Paulo, Brasil. As linhas tracejadas indicam os envelopes de confiança pelas simulações do Método Montecarlo a $99 \%$, para a Completa Aleatoriedade Espacial (CAE). As linhas contínuas demonstram o ajuste pela Função K de Ripley transformado $(L(s))$.

FIGURE 7: Spatial pattern observed for higher density species at (a) 'Cerradão, (b) Seasonal Forest, (c) Ombrophilous Forest and (d) Forest of 'Restinga' in São Paulo, Brazil. Dashed lines represent the confidence envelopes ( $99 \%$ ) by Montecarlo method simulations for a complete spatial randomness (CAE). Solid lines demonstrate the adjustment for transformed Ripley's $\mathrm{K}$ function $(L(s))$. 
mas em densidade menor. Rejeição à aleatoriedade foi observada até $90 \mathrm{~m}$ de distância para Guapira opposita, de modo que, a partir desta escala o padrão espacial, foi significativamente aleatório. De fato, seu padrão assemelha-se até ao das duas espécies anteriores, não fosse pela aleatoriedade em escalas maiores. A observação da figura destas três espécies já salienta esta semelhança.

$\mathrm{Na}$ Floresta Ombrófila, três das quatro espécies de maior densidade apresentaram padrão espacial agregado em todas as escalas, salientado o caráter fortemente agregado do padrão espacial das árvores desta formação florestal. Fica evidente a importância do palmiteiro Euterpe edulis na comunidade, não só em função da sua densidade entre as espécies mais abundantes, como também do seu papel na composição do dossel e sub-bosque da floresta.

\section{Restinga}

O padrão espacial para as quatro espécies de destaque na Ilha do Cardoso é descrito na Figura $7 \mathrm{~d}$. A espécie de maior densidade na Floresta Ombrófila também teve o mesmo papel na Restinga: Euterpe edulis, com 266 indivíduos.ha-1 ${ }^{-1}$ Novamente, a espécie dominante se sobressai quando comparado seu número de indivíduos com o das outras espécies.

A Completa Aleatoriedade Espacial foi rejeitada para Euterpe edulis, Amaioua intermedia e Xylopia langsdorffiana. Padrão agregado entre 10 e 120 m de distâncias foi observado para Andira anthelmia.

A espécie Euterpe edulis parece desempenhar papel importante na dinâmica da Floresta Ombrófila e da Restinga. O fato de a espécie ser a mais abundante nas duas áreas já seria suficiente para justificar especial atenção. A espécie possui papel fundamental para a fauna, em razão do grande número de sementes e frutos produzidos, e para a composição de ambos os estratos da floresta, uma vez que é comum observar grande número de plântulas no sub-bosque dos remanescentes florestais. Por este motivo, a espécie é apontada como fundamental na recuperação de florestas secundárias (DIAS, 1993).

Espécies que preferem luz difusa ou necessitam de sombra ao longo do seu ciclo de vida (espécies esciófitas), como Amaioua intermedia, Euterpe edulis (sobretudo em estágios iniciais de vida), Trichilia clausenii e Aspidosperma polyneuron, apresentaram padrões agregados. Espécies que crescem a pleno sol (heliófitas), como Copaifera langsdorfi, Ocotea corymbosa, Xylopia aromatica e Vochysia tucanorum, espécies dominantes no Cerradão de Assis, também apresentaram padrões agregados em todas as escalas. Apenas para Metrodorea nigra, em Caetetus, o padrão aleatório foi notado a partir de 75 m de distância.

\section{CONCLUSÕES}

Segundo os resultados observados, podese dizer que: (1) Os padrões espaciais das quatro formações florestais do Estado de São Paulo produziram padrões espaciais distintos em cada floresta. Devido aos diferentes processos ecológicos e pelas características ambientais locais. Sendo que, o padrão espacial na Floresta Ombrófila foi bem diferente dos demais e houve grande semelhança entre a distribuição espacial das espécies do Cerradão e da Restinga. (2) O padrão espacial das espécies acompanhou, em linhas gerais, o padrão espacial das comunidades. Padrões agregados foram encontrados para a maioria das espécies em questão, em sua superioridade de espécies dominantes. Quando comparados os padrões espaciais de espécies presentes em diferentes formações florestais, pequenas diferenças foram observadas, embora, ainda seja difícil identificar claramente a sua razão. Assume-se que características intrínsecas àquelas espécies, como sua fenologia, síndromes de dispersão e polinização, estratégias de ocupação de habitats disponíveis e potencial competitivo possam explicar seu comportamento, no que se refere ao padrão espacial, frente a ambientes tão diferentes. (3) Embora tenha sido observado que as árvores em geral tendem a agrupar-se, da mesma forma que árvores de tamanho menor tendem a formar grupos mais definidos do que árvores de tamanho maior, o tamanho dos grupos e a escala de distâncias em que tais grupos ocorreram, em cada formação florestal, indicam sutilezas na estrutura de cada comunidade estudada.

\section{AGRADECIMENTOS}

À fundação que apoiou o desenvolvimento deste trabalho. FAPESP (01/11825-3; 1999/09635$0)$.

\section{REFERÊNCIAS BIBLIOGRÁFICAS}

ANJOS, A. Análise do padrão de distribuição 
espacial da araucária (Araucaria angustifólia) em algumas áreas no Estado do Paraná, utilizando a função K de Ripley. Scientia Forestalis, Piracicaba, n. 66, p. 38-45, 2004.

ANJOS, A. et al. Análise do efeito de um manejo em regime de rendimento sustentável sobre o padrão de distribuição espacial do palmiteiro (Euterpe edulis Martius), utilizando a Função k de Ripley. Árvore, Viçosa, v. 22, n. 2, p. 215-225. 1998.

ARMESTO, J. et al. A comparison of spatial patterns of trees in some tropical and temperate forests. Biotropica, Washington, v. 8, n. 1, p. 1-11. 1986. BAROT, S. et al. Demography of a savanna palm tree: predictions from comprehensive spatial pattern analyses. Ecology, Oxford, v. 80, p. 1987-2005, 1999.

BATISTA, J. Spatial dynamics of trees in a brazilian atlantic tropical forest under natural and managed conditions. 1994. $330 \mathrm{f}$. Thesis (PhD thesis)-University of Washington, Seattle, 1994.

BATISTA, J.; MAGUIRE, D. Modelling the spatial structure of tropical forests. Forest Ecology and Management, Amsterdam v. 110, p. 293-314, 1998. BUSING, R. Composition, structure and diversity of cove forest stands in the great smoky mountains: a patch dynamics perspective. Journal of Vegetation Science, Knivsta, v. 9, p. 881-890, 1998.

CAPRETZ, R. L. Análise dos padrões espaciais de árvores em quatro formações florestais do Estado de São Paulo, através de análises de segunda ordem, como a Função K de Ripley. 2004. 93 f. Dissertação (Mestrado em Ecologia)Escola Superior de Agricultura Luiz de Queiroz, Piracicaba, 2004.

CAPRETZ, R. L. et al. O uso de análises de segunda ordem (função $\mathrm{k}$ de Ripley) para a detecção do padrão espacial em três áreas submetidas a manejos silviculturais diferentes na região de Paragominas, Pará. In: REUNIÃO DA RBRAS, 48.; SEAGRO, 10., 2003, Belo Horizonte. Anais ... Lavras: Universidade Federal de Lavras, 2003, p.192-196.

COLLINS, S.; KLAHR, S. Tree dispersion in oakdominated forests along an environmental gradient. Oecologia, Berlim, v. 86, p. 471-477, 1991.

CONDIT, R. et al. Recruitment near conspecific adults and the maintenance of tree and shrub diversity in a neotropical forest. American Naturalist, Chicago, v. 140, p. 261-286, 1992.

CONDIT, R. et al. Spatial patterns in the distribution of tropical tree species. Science, Inglaterra, v. 288, n. 5470, p. 1414-1418, 2000.

CONNELL, J. Diversity in tropical rain forests and coral reefs. Science, Londres, v. 199, p. 1302-1310. 1978.

CONNELL, J. H. On the role of natural enemies in preventing competitive exclusion in some marine animals and in rain forest trees. In: DEN BOER, P. J. GRADWELL, G. (ed). Dynamics of populations. PUDOC, 1971. p. 298-312.

COOMES, D. et al. Identifying aggregation and association in fully mapped spatial data. Ecology, Oxford, v. 80, p. 554-565, 1999.

DEMELAS, K. M.; PEDRONI, F.; SANCHEZ, M. Estrutura e Dinâmica Populacional de Copaíba (Copaifera langsdorffii Desf. FabaceaeCaesalpinioideae) em uma área de Mata de Galeria, Barra do Garças-MT. In: CONGRESSO NACIONAL DE BOTÂNICA, 58., 2007, São Paulo. Anais... São Paulo, 2007.

DIAS, A. Estrutura e diversidade do componente arbóreo e a regeneração do palmito (Euterpe edulis) em um trecho de mata secundária, no parque estadual de Carlos Botelho, SP. 1993. 126 f. Dissertação (Mestrado em Recursos Florestais)Escola Superior de Agricultura Luiz de Queiroz, Piracicaba, 1993.

DIGGLE, P. Statistical analysis of spatial point patterns. 2. ed. London: Arnold, 2003. 159 p.

DIGGLE, P. Statistical analysis of spatial point patterns. London: Academic Press. 1983. 272 p.

EDMAN, M.; JONSSON, B. Spatial pattern of downed $\operatorname{logs}$ and wood-decaying fungi in an oldgrowth picea abies forest. Journal of Vegetation Science, Knivsta, v. 12, p. 609-620, 2001.

FONSECA, M. G.; MARTINI, A. M; DOS SANTOS, F. A. Spatial structure of Aspidosperma polyneuron in two semideciduous forests in Southeast Brazil. Journal of Vegetation Science, Knivsta, v. 15, p. 41-48, 2004.

FRANCO, G. Florística e fitossociologia de duas unidades do mosaico florestal da Estação Ecológica de Caetetus floresta estacional semidecidual, Gália, SP. 2002. 95 f. Dissertação (Mestrado em Ciências)-Escola Superior de Agricultura Luiz de Queiroz, Piracicaba, 2002.

GETIS, A.; FRANKLIN, J. Second-order neighbourhood analysis of mapped point patterns. Ecology, Oxford, v. 68, p. 473-477, 1987.

GRAU, H. Regeneration patterns of Cedrela lilloi (Meliaceae) in Northwestern Argentina subtropical montane forests. Journal of Tropical Ecology, Cambridge, v. 16, p. 227-242, 2000.

HAASE, P. et al. Spatial pattern in Anthyllis cytisoides shrubland on abandoned land in 
southeastern Spain. Journal of Vegetation Science, Knivsta, v. 8, p. 627-634, 1997.

HAASE, P. Spatial pattern analysis in ecology based on ripley's $\mathrm{k}$ function: introduction and methods of edge correction. Journal of Vegetation Science,
Knivsta, v. 6, p. 575-582, 1995.

HARMS, K. et al. Habitat associations of trees and shrubs in a 50 ha neotropical forest plot. Journal of Vegetation Science, Knivsta, v. 11, p. 801-812, 2001. 